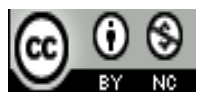

Jurnal Pendidikan IPS Indonesia is licensed under

A Creative Commons Attribution-Non Commercial 4.0 International License

\title{
PEMANFATAN SI MACAN UNTUK MENINGKATKAN KREATIVITAS BERFIKIR PESERTA DIDIK PADA MATA PELAJARAN GEOGRAFI DI KELAS X IIS 2 SMAN 1 PURWANTORO TAHUN PELAJARAN 2016/2017
}

\author{
Dony Purnomo \\ SMAN 1 Purwantoro, Jl.Raya Tegalrejo-Purwantoro Wonogiri \\ E-mail: donypurnomo88@gmail.com
}

\begin{abstract}
Penelitian ini bertujuan untuk (1)Memberikangambaran pemanfaatan Si Macan untuk meningkatkan kreativitasberfikir peserta didik pada mata pelajaran geografi di kelas X IIS 2 SMAN 1 Purwantoro tahun pelajaran 2016/2017 (2) Mengetahui peningkatan kreativitas berfikir peserta didik pada mata pelajaran geografi di kelas X IIS 2 SMAN 1 Purwantoro tahun pelajaran $2016 / 2017$. Penelitian ini merupakan penelitian tindakan kelas yang mengambil sampel kelas X IIS 2 pada tahun pelajaran 2016/2017 sejumlah 26 peserta didik. Dalam penelitian ini menggunakan sumberdata primer yang berupa angket, observasi dan dokumentasi. Hasil penelitian diperoleh kesimpulan bahwa: (1)Pemanfaatan Si Macan dalam meningkatkan kreativitas berfikir peserta didik di kelas X IIS 2 SMAN 1 Purwantoro tahun pelajaran 2016/2017 melalui tiga tahapan yaitu: tahap kondisi awal dilakukan perencanaan dilanjutkan dengan melaksanakan tindakan pada siklus 1 dilakukan refleksi untuk diperbaiki dalam siklus 2. (2) Dengan pemanfaatan Si Macan dapat meningkatkan kreativitas berfikir peserta didik di kelas X IIS 2 SMAN 1 Purwantoro tahun pelajaran 2016/2017 pada indikator Fluency, Flexibility dan Novelty.
\end{abstract}

\section{Pendahuluan}

Hakekatnya kegiatan pembelajaran adalah suatu proses interaksi atau hubungan timbal balik antara guru dan peserta didik dalam satuan proses pembelajaran. Masalah pendidikan tidak dapat terlepas dari masalah pembelajaran, karena pembelajaran merupakan inti dari proses peningkatan kualitas pendidikan. Keefektifan pembelajaran dapat tergambar dari pencapaian peserta didik selama proses pembelajaran.

Mata pelajaran geografi merupakan salah satu mata pelajaran yang mendorong peserta didik untuk memiliki kemampuan dan mengembangkan pemahaman tentang variasi dan organisasi spasial masyarakat, tempat dan lingkungan di bumi. Pada mata pelajaran geografi,peserta didik didorong untuk memahami aspek dan proses fisik yang membentuk pola bumi, karakteristik dan persebaran spasial ekologis di permukaan bumi.

Kenyataan yang sering dihadapi di dalam pembelajaran geografi adalah anggapan jika mata pelajaran hanya bersifat teoretis dan peserta didik mempelajari materi berdasarkan hafalan, dengan adanya anggapan bahwa pembelajaran geografi hanya bersifat teoretis, menimbulkan kreativitas peserta didik berkembang kurang optimal. Sehingga peserta didik merasa bosan karena hanya menghafal teori teori tanpa adanya rangsangan untuk menalar dan berkreasi.

Adanya potensi dan kreativitas yang dimiliki setiap anak, maka anak membutuhkan aktivitas dalam pembelajaran yang mewadahi ideide kreatif mereka.Untuk mengelola dan membangkitkan kreativitas anak, para pendidik harus melakukan pemebalajaran yang dapat 
menunjang tumbuhnya kreativitas dan terus dipupuk agar kreativitas mereka tidak hilang.

Dengan adanya fakta tersebut diperlukan adanya inovasi pembelajaran yang mampu membangkitkan kreativitas peserta didik dalam berfikir dan berkreasi.Untuk mewujudkan inovasi pembelajaran, guru perlu mengembangkan situasi pembelajaran yang banyak memberi kesempatan kepada peserta didik untuk memecahkan masalah, melakukan beberapa percobaan, mengembangkan gagasan,serta mengemas materi pembelajaran secara kreatif sehingga mata pelajaran geografi menjadi menarik untuk dipelajari.

Rumusan masalah dalam penelitian ini adalah: (1) Bagaimanakah pemanfaatan Si Macan untuk meningkatkan kreativitasberfikir peserta didik pada mata pelajaran geografi di kelas X IIS 2 SMAN 1 Purwantoro tahun pelajaran 2016/2017? (2) Apakah $\mathrm{Si}$ Macandapat meningkatkan kreativitasberfikir peserta didik pada mata pelajaran geografi di kelas X IIS 2 SMAN 1 Purwantoro tahun pelajaran 2016/2017?

Adapun tujuan dalam penelitian ini adalah : (1) Memberikangambaran pemanfaatan Si Macan untuk meningkatkan kreativitasberfikir peserta didik pada mata pelajaran geografi di kelas X IIS 2 SMAN 1 Purwantoro tahun pelajaran 2016/2017 (2) Mengetahui peningkatan kreativitas berfikirpeserta didikpada mata pelajaran geografi di kelas X IIS 2 SMAN 1 Purwantoro tahun pelajaran 2016/2017.

\section{LANDASAN TEORI}

1. Kreativitas

Reni Akbar Hawadi (2001: 5) mengemukakan bahwa kreativitas merupakan kemampuan seseorang untuk melahirkan sesuatu yang baru, baik berupa gagasan maupun karya nyata, baik dalam bentuk ciriciri aptitude maupun non aptitude, baik dalam karya baru maupun kombinasi dengan hal-hal yang sudah ada, yang semuanya itu relatif berbada dengan apa yang telah ada sebelumnya.

2. Hakikat Pembelajaran Geografi

Sumaatmadja (1997: 11) menerangkan bahwa pengertian geografi dalam seminar lokakarya peningkatan kualitas pengajaran geografi di Semarang tahun 1988, adalah ilmu yang mempelajari persamaan dan perbedaan fenomena geosfer dengan sudut pandang lingkungan dan kewilayahan dalam kontek keruangan" Fungsi pengajaran geografi adalah mengembangkan kemampuan peserta didik dalam mengenali dan memahami gejala alam dan kehidupan di muka bumi serta interaksi antar manusia dengan lingkungan alam kaitanya dengan hubungan atau susunan keruangan dan kewilayahan.

Pembelajaran geografi membangundan mengembangkan pemahaman peserta didik tentang variasi dan organisasi spasialmasyarakat, tempat dan lingkungan pada muka bumi peserta didik didorong utukmemahami aspek dan proses fisik yang membentuk poal muka bumi, karakteristikdan persebaran spasial ekologis dipermukaan bumi. Selain itu peserta didikdimotivasi secara aktif dan kreatif untuk menelaah bahwa kebudayaan danpengalaman mempengaruhi persepsi manusia tentang tempat dan wilayah.

3. Pemanfaatan Si Macam

$\mathrm{Si}$ macan merupakan akronim dari Kreasi Mading Cakap Aktif dan Menyenangkan.Majalah dinding yang sering kita sebut dengan istilah mading adalah majalah yang dikelola secara sederhana oleh suatu lembaga.Majalah dinding merupakan majalah yang berisikan tempelan materi pada suatu media biasanya berupa kertas asturo.

Dari uraian di atas, mading merupakan media yang dapat sebagai kumpulan karya ataupun fortopolio peserta didiksehingga menjadi media yang cukup menarik untuk belajar. Jika majalah dinding maupun majalah sekolah tersebut dimanfaatkan secara maksimal oleh seorang guru yang kreatif, ia akan menjadi salah satu media dan sumber belajar yang cukup menarik dan memotivasi peserta didik untuk belajar. 


\section{METODE PENELITIAN}

Penelitian dilakukan di SMAN 1 Purwantoro kelas X IIS 2 SMAN 1 Purwantoro tahun pelajaran 2016/2017 yang berjumlah 26 peserta didik.Penelitian dilakukan kurun waktu bulan Februari-Maret 2017.

Data yang dikumpulkan dalam penelitian ini adalah kreativitas berfikir peserta didik dalam pembelajran geografi.Teknik pengumpulan data dalam penelitian ini melalui observasi, dokumentasi dan angket.

Metode penelitian ini menggunakan penelitian tindakan kelas dengan dua siklus perlakukan tindakan dan pengamatan satu kondisi awal sebagai pembanding setelah ada perlakuan siklus. Adapaun kerangka penelitian ini adalah sebagai berikut:

\begin{tabular}{|c|}
\hline PERENCANA \\
AN \\
TINDAKAN \\
- Identifikasi \\
\hline
\end{tabular}

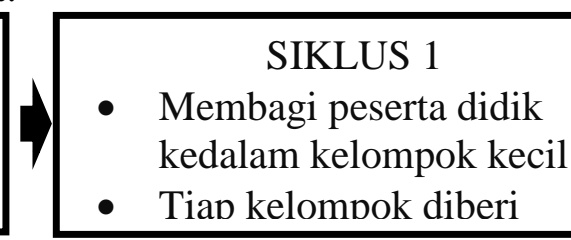

\begin{tabular}{|c|}
\hline $\begin{array}{c}\text { REFLEKSI } \\
\text { DAN } \\
\text { PERENCANA }\end{array} / 4 \begin{array}{l}\text { OBSERVASI } \\
\text { Observasi kegiatan peserta } \\
\text { didik }\end{array}$ \\
\hline
\end{tabular}

\section{SIKLUS 2}

- Membagi peserta didik kedalam kelompok kecil

- Tiap kelompok diberi materi sesuai dengan

Gambar 1. Bagan Alir Penelitian

Dalam penelitian ini, penilaian kreativitas berfikir menggunakan model rubrik yang berpedoman pada indikator penialain berpikir kreatif peserta didik (kefasihan, fleksibilitas dan kebaruan). Rubrik tersebut menggunakan pengajuan masalah dan pemecahan masalah yang dikembangkan oleh Silver (1997).

Skala penskoran, rubrik ini berisi empat tingkatan pencapaian, maka bentuk kuantitatifnya antara 1 sampai 4. Dari skala penilaian tersebu,t akan dibuat penskoran dengan rentang tiap kriteria yang sama untuk setiap kriteria, yaitu fluency, flexibility dan novelty.

\section{HASIL DAN PEMBAHASAN}

Hasil penelitian ini mencakup temuan dan analisis selama pembelajaran pada materi atmosfer.Pelaksanaan tindakan melalui dua siklus yang terdiri dari perencanaan tindakan, pelaksanaan tindakan dan refleksi dari tindakan yang telah dilaksanakan.

\section{Kondisi Awal}

Dari hasil observasi pada kondisi awal menunjukkan bahwa hasil penilaian indikator kreativitas peserta didik mayoritas masih berada pada kategori cukup dan baik. Dan pada indikator kebaruan masih terdapat $15,38 \%$ dari siswa yang berkategori kurang.

Tabel 1. Hasil Penilaian Indikator Kreativitas Kondisi Awal

\begin{tabular}{|l|c|c|c|c|}
\hline \multirow{2}{*}{ Indikator Kreativitas } & \multicolumn{4}{|c|}{ Kategori } \\
\cline { 2 - 5 } & $\begin{array}{c}\text { Kurang } \\
(\%)\end{array}$ & $\begin{array}{c}\text { Cukup } \\
(\%)\end{array}$ & $\begin{array}{c}\text { Baik } \\
(\%)\end{array}$ & $\begin{array}{c}\text { Sangat } \\
\text { baik (\%) }\end{array}$ \\
\hline Fluency (Kefasihan) & 11.54 & 23.08 & 53.85 & 11.54 \\
\hline $\begin{array}{l}\text { Flexibility } \\
\text { (Fleksibel) }\end{array}$ & 7.69 & 30.77 & 46.15 & 15.38 \\
\hline Novelty (Kebaruan) & 15.38 & 34.62 & 26.92 & 23.08 \\
\hline
\end{tabular}

Dari hasil analisis data di atas, maka perlu adanya pembelajaran yang mampu menumbuhkembangkan kreativitas peserta didik sehingga dapat berkategori baik dan sangat baik dalam setiap indikatornya.

\section{Deskripsi Siklus 1}

Dari hasil analisis pada kondisi awal, selanjutnya dilakukan tindakan yaitu dengan memanfaatkan Si Macan untuk meningkatkan kreativitas peserta didik dalam pembelajaran.Langkah pembelajaran pada siklus 1 yaitu pembukaan, materi inti dan penutup. Dalam materi inti, peserta didik dibagi kedalam lima kelompok yang beranggotakan lima orang untuk tiap kelompoknya. Selanjutnya tiap anggota kelompok dapat berkreasi dan berpartisipasi dalam membuat mading sesuai dengan materinya.

Setelah selesai membuat mading, setiap kelompok mempresentasikan madingnya sesuai dengan materi yang telah menjadi bagiannya. Kemudian dilakukan tanya jawab sesuaidengan materi yang telah dipresentasikan. 


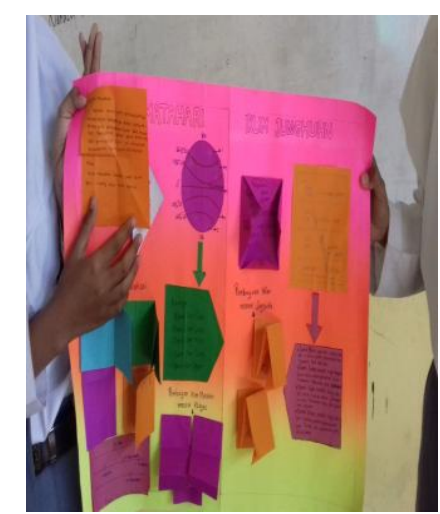

at Mading dan Presentasi Karyanya Pada Siklus 1

ada kegiatan pembelajaran siklus 1 peserta didik nampak antusias dalam mengikuti pembelajaran. Dari hasil analisis observasi siklus 1, mayoritas peserta didik dalam kategori baik dan sudah terdapat kenaikan presentase indikator kreativitas. Hal tersebut jika dibandingkan dengan kondisi awal sebelum dilakukan tindakan siklus 1. Lebih lengkapnya disajikan dalam tabel berikut:

Tabel 2. Hasil Penilaian Indikator Kreativitas Pada Siklus 1

\begin{tabular}{|l|c|c|c|c|}
\hline \multirow{2}{*}{$\begin{array}{c}\text { Indikator } \\
\text { Kreativitas }\end{array}$} & \multicolumn{4}{|c|}{ Kategori } \\
\cline { 2 - 5 } & $\begin{array}{c}\text { Kurang } \\
(\%)\end{array}$ & $\begin{array}{c}\text { Cukup } \\
(\%)\end{array}$ & $\begin{array}{c}\text { Baik } \\
(\%)\end{array}$ & $\begin{array}{c}\text { Sangat } \\
\text { baik (\%) }\end{array}$ \\
\hline $\begin{array}{l}\text { Fluency } \\
\text { (Kefasihan) }\end{array}$ & 7.69 & 19.23 & 57.69 & 15.38 \\
\hline $\begin{array}{l}\text { Flexibility } \\
\text { (Fleksibel) }\end{array}$ & 3.85 & 23.08 & 53.85 & 19.23 \\
\hline $\begin{array}{l}\text { Novelty } \\
\text { (Kebaruan) }\end{array}$ & 11.54 & 26.92 & 34.62 & 26.92 \\
\hline
\end{tabular}

Dari tabel di atas menunjukkan masih ada indikator fluency yang berkategori kurang yaitu 7,69\%, karena terdapat 2 peserta didik yang belum dapat menyampaikan materi bagiannya dengan baik. Pada indikator flexibility masih ada yang berkategori kurang sebesar 3,85\%, karena terdapat satu peserta didik yang menyampaikan materi dengan cara membaca dan menyalin seperti dibuku. Sedangkan pada indiaktor noveltyterdapat 11,54\% yang berada pada kategori kurang, karena ada 3 peserta didik yang menyampaikan materi tidak sesuai dengan perkembangan saat ini. Hal tersebut dikarenakan sumber belajar yang digunakan sudah lama. Kekurangan dalam siklus 1 dilakukan refleksi dan diperbaiki dalam siklus 2 .

\section{Deskripsi Siklus 2}

Berdasarkan refleksi pada siklus 1 selanjutnya dilakukan perbaikan pada siklus 2 , dengan tahapan pembelajaran yang samaseperti siklus 1. Perbaikan pada siklus 2 ini adalah penguatan dan pengarahan terhadap materi yang telah menjadi bagian tiap peserta didik.Dalam siklus 2 ini, guru juga memberikan motivasi untuk memacu kreativitas perserta didik dalam menyampaiakn gagasan dan materi yang telah menjadi bagiannya.

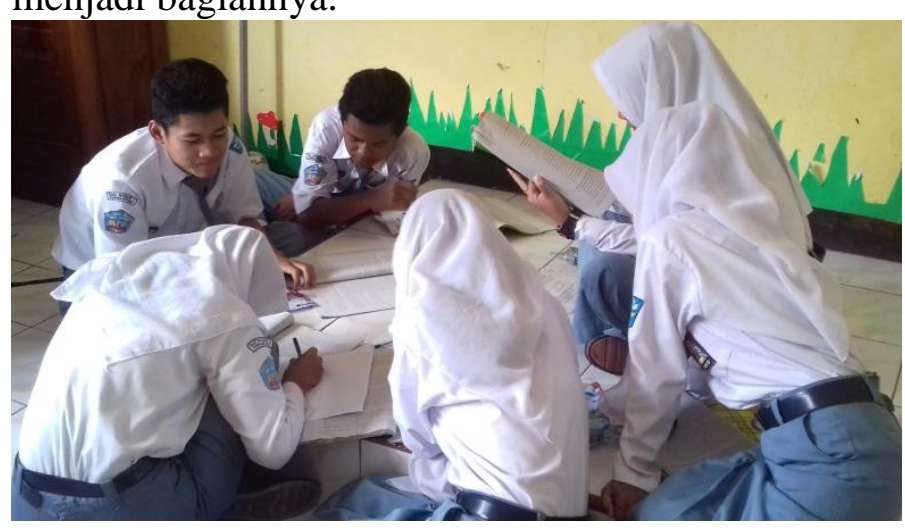

Gambar 3. Peserta Didik Membuat Mading da Pada siklus 2, peserta didik telah menunjukkan perubahan dalam hal berfikir keratif.Mereka lebih intens ketika berdiskusi pada kelompok, dan hasil produk yang dihasilkan juga sudah mengalami perubahan kearah yang lebih baik.Adapun lebih lengkapnya disajikan dalam tabel berikut:

Tabel 2. Hasil Penilaian Indikator Kreativitas Pada Siklus 2

\begin{tabular}{|l|c|c|c|c|}
\hline \multirow{2}{*}{$\begin{array}{l}\text { Indikator } \\
\text { Kreativitas }\end{array}$} & $\begin{array}{c}\text { Kurang } \\
(\%)\end{array}$ & $\begin{array}{c}\text { Cukup } \\
(\%)\end{array}$ & $\begin{array}{c}\text { Baik } \\
(\%)\end{array}$ & $\begin{array}{c}\text { Sangat baik } \\
(\%)\end{array}$ \\
\cline { 2 - 5 } $\begin{array}{l}\text { Fluency } \\
\text { (Kefasihan) }\end{array}$ & 0 & 7.69 & 38.46 & 53.85 \\
\hline $\begin{array}{l}\text { Flexibility } \\
\text { (Fleksibel) }\end{array}$ & 0 & 11.54 & 30.77 & 57.69 \\
\hline $\begin{array}{l}\text { Novelty } \\
\text { (Kebaruan) }\end{array}$ & 0 & 7.69 & 30.77 & 61.54 \\
\hline
\end{tabular}

Berdasarkan tabel di atas kreativitas peserta didik sudah mengalami kenaikan dibandingkan dari siklus 1 . Hal ini terbukti dengansudah tidak adanya peserta didik yang memiliki kategori kurang pada semua indikator. Dalam siklus 2, sebagian peserta didik berada pada kategori baik dan sangat baik. Adapun peningkatan kreativitas peserta didik dari siklus 1 dan 2 pada tiap indikator ditampilkan dalam grafik berikut : 


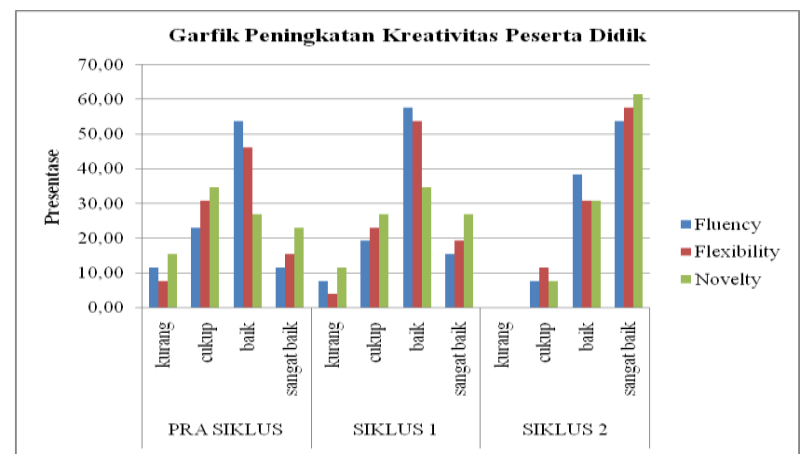

Gambar 4. Grafik Peningkatan Kreativitas Peserta Didik Tiap Siklus

\section{KESIMPULAN}

Dari hasil penelitian dan pembahasan di atas dapat disimpulkan bahwa:

1. Pemanfaatan Si Macan dalam meningkatkan kreativitas berfikir peserta didik di kelas $X$ IIS 2 SMAN 1 Purwantoro tahun pelajaran 2016/2017 melalui tiga tahapan yaitu: tahap kondisi awal dilakukan perencanaan dilanjutkan dengan melaksanakan tindakan pada siklus 1 dilakukan refleksi untuk diperbaiki dalam siklus 2

2. Pemanfaatan Si Macan dapat meningkatkan kreativitas berfikir peserta didik di kelas $\mathrm{X}$ IIS 2 SMAN 1 Purwantoro tahun pelajaran 2016/2017 pada indikator Fluency, Flexibility dan Novelty.

\section{DAFTAR PUSTAKA}

Harijanti, Nur Sri. 2007. Peningkatan Partisipasi Dan Kreativitas Siswa Pada Mata Pelajaran Geografi Dengan Model Assure Di Kelas X D Man Tempursari Mantingan Ngawi . Tesis Magister, tidak dipublikasikan, Universitas Sebelas Maret Surakarta, Surakarta.

Molenda, M\&Heinich, R, JD Russel and Smaldito, S.E. (2005). Instructional Technology and Media for Learning. New Jersey : Pearson Education Inc.

Reni Akbar Hawadi, Wihardjo, DS dan Mardi Wiyono. 2001. Kreativitas.Jakarta : Grasindo
Silvia,Fiki dkk.2015.Pengembangan Rubrik Keterampilan Berpikir Kreatif dalam Memecahkan Masalah Matematika Siswa Kelas VIII SMP Attaufiq Jambi. Edu-Sains Volume 4 No. 1, Januari 2015

Silver, Edward A. 1997.Fostering Creativity through Instruction Rich in Mathematical Problem Solving and Thinking in Problem Posing.http://www.emis.de/journals/ZDM/ zd m973i.html. Volume 29 (June1997) Number Electronic Edition ISSN 1615679X. Diakses tanggal 17 Januari 2017.

Sumaatmadja, Nursid.1997. Metodologi Pengajaran Geografi. Jakarta: Bumi Aksara

Utami Munandar. 1992. Mengembangkan Bakat dan Kreativitas Anak Sekolah.Jakarta : Grasindo 